\title{
ADUBAÇÃO NITROGENADA, POTÁSSICA E FOSFATADA NA PRODUÇÃO E GERMINAÇÃO DE SEMENTES DE CAPIM QUICUIO-DA-AMAZÔNIA
}

\author{
BRUNO BORGES DEMINICIS² ${ }^{2}$ HENRIQUE DUARTE VIEIRA ${ }^{3}$, \\ ROBERTO FERREIRA DA SILVA ${ }^{4}$, JOÃO BATISTA RODRIGUES DE ABREU 5 , \\ SAULO ALBERTO DO CARMO ARAÚJO ${ }^{6}$, JÚLIA GAZZONI JARDIM ${ }^{7}$
}

\begin{abstract}
RESUMO - Devido à falta de informações relacionadas à adubação de plantas forrageiras para a produção de sementes, nota-se a necessidade de se estudar a influência de doses de nutrientes que proporcionem aumento de produtividade e obtenção de sementes de melhor qualidade. Foram realizados dois experimentos com o objetivo de verificar o efeito de doses de nitrogênio e fósforo e de doses de nitrogênio e potássio sobre a produção e qualidade de sementes de Brachiaria humidicola (Rendle) Schweick. Em ambos, o delineamento experimental utilizado foi o de blocos ao acaso em esquema fatorial, com quatro repetições, sendo no primeiro experimento: quatro doses de nitrogênio $(0,100,200$ e $400 \mathrm{Kg} / \mathrm{ha})$ e quatro doses de potássio $(0,100,200$ e $400 \mathrm{Kg}$ / ha) e no segundo: três doses de nitrogênio $(0,100$ e $200 \mathrm{Kg} / \mathrm{ha})$ e três doses de fósforo $(0,50$ e 75 $\mathrm{Kg} / \mathrm{ha}$ ) A colheita das sementes ocorreu 24 dias após início da emergência das inflorescências (de 5 a 10 inflorescências $/ \mathrm{m}^{2}$ ). As sementes foram pesadas e contadas. Os resultados evidenciaram o efeito $(\mathrm{P}<0,05)$ da adubação nitrogenada na produção, tanto em peso quanto em número, e na germinação das sementes, porém a adubação com fósforo e potássio não tiveram efeito sobre a produção e qualidade das sementes.
\end{abstract}

Termos para indexação: fertilização, sementes, Brachiaria humidicola.

\section{SEED QUALITY AND PRODUCTION OF Brachiaria humidicola SUBMITED TO NITROGEN, PHOSPHORUS AND POTASSIUM FERTILIZERS RATES}

\begin{abstract}
There exists a lack of information about the fertilization of forages plants when the seeds production is the final purpose. Thus the study of influence of nutrients doses is necessary for increase the productivity and to obtained seeds with superior quality. Two experiments were carried out to evaluate the influence of effect of doses of nitrogen, phosphorus and potassium on the quality and seed production of koronivia grass. The experimental design used in the two experiments was a randomized blocks replicated with four repetitions. In the first experiment was used four nitrogen doses $(0,100,200$ and $400 \mathrm{Kg} / \mathrm{ha})$ and four potassium doses $(0,100,200$ and $400 \mathrm{Kg} / \mathrm{ha})$ and in the second experiment was used three nitrogen doses $(0,100$ and 200 $\mathrm{Kg} / \mathrm{ha})$ and three phosphorus doses $(0,50$ and $75 \mathrm{Kg} / \mathrm{ha})$. The seeds harvest was accomplished 24
\end{abstract}

${ }^{1}$ Submetido em 25/08/2009. Aceito para publicação em 04/02/2010.

${ }^{2}$ Zootecnista, M.Sc. Produção Animal, MBA em Agribusiness, Doutorando em Produção Vegetal LFIT/CCTA/UENF, CEP 28013-602, brunodeminicis@hotmail.com.

${ }^{3}$ Eng. Agr. D.Sc., Professor Associado, LFIT/CCTA/UENF, henrique@uenf.br.

${ }^{4}$ Eng. Agr., D.Sc., Professor Titular 1, LFIT/CCTA/UENF, roberto@uenf.br.
${ }^{5}$ Zootecnista, D.Sc., Professor Adjunto, DNAP/IZ/UFRuralRJ, jbrabreu@ufrrj.br.

${ }^{6}$ Zootecnista, D.Sc. Produção Animal, Pós-Doutorando em Zootecnia, UFRRJ, araujosac@yahoo.com.br.

${ }^{7}$ Graduanda em Zootecnia, UNIOESTE, jugazzoni@hotmail.com. 
days after beginning of the emergency of the flowers (from 5 to 10 flowers $/ \mathrm{m}^{2}$ ). The seeds were counting and weighted. The results evidenced the effect $(\mathrm{P}<0,05)$ of the nitrogen fertilization in the production, in weight and in number, and quality of seeds, however the fertilizatin with phosporus and potassium didn’t show any effects.

Index terms: fertilization, seeds, koronivia grass.

\section{INTRODUÇÃO}

Em pouco mais de trinta anos, o Brasil passou da condição de importador para a de exportador e, também, maior produtor de sementes de forrageiras do mundo (Andrade et al., 2004), sendo que o maior volume é constituído por sementes de Brachiaria spp e Panicum spp.. Grande parte das sementes produzidas tem sido comercializada internamente, e o restante é exportado, principalmente, para países da América do Sul e Central (Fernandes et al., 2005). A liderança do Brasil no mercado mundial de sementes de forrageiras depende da sua capacidade de produzir produtos que atendam a demanda, com baixo custo. Esse setor representa um faturamento de milhões de dólares e a manutenção de milhares de emprego, embora os investimentos em pesquisa com estas espécies sejam modestos e a qualidade das sementes produzidas, muitas vezes, deixa a desejar (Dias e Alves, 2001). A produção de sementes forrageiras visando atender à demanda de formação e/ou reforma de pastagens vem gradativamente alcançando níveis tecnológicos adequados e coerentes com a importância da atividade, ou seja, a produção de sementes utilizando técnicas rudimentares, sem controle de qualidade está diminuindo (Pereira, 2000). Apesar disto, o mercado nacional ainda é dominado pelas forrageiras do gênero Brachiaria, com sistemas de produção de sementes variando, entre os produtores, de altamente especializado a ocasional sem técnicas adequadas (Andrade, 2001).

As forrageiras do gênero Brachiaria merecem atenção especial dos pesquisadores, haja vista que a maior parte das pastagens em território nacional é formada por essas gramíneas. O predomínio de Brachiaria humidicola decorre do fato de ser pouco exigente em fertilidade do solo, tolerante ao alumínio e não requerer altos teores de fósforo para seu desenvolvimento (Botrel, 1999). Além disso, compete eficientemente com as plantas invasoras, formando pastagens densas que protegem o solo contra a erosão (Skerman e Riveiros, 1990). Todavia, estas plantas foram pouco estudadas do ponto de vista da produção comercial de sementes e apresentam história recente de manipulação genética e agronômica (Souza, 2001). Sabe-se também que, não raramente, as condições edafoclimáticas e geográficas necessárias à maior expressão dos potenciais de produção de sementes, destas plantas, não coincidem com aquelas necessárias à maior expressão dos seus potenciais forrageiros.

Segundo Conde e Garcia (1988) a qualidade e a produtividade de sementes estão, em grande parte, relacionadas com fornecimento adequado de nutrientes às plantas, principalmente nitrogênio. Fagundes et al. (2005) verificaram que o suprimento de nitrogênio $(\mathrm{N})$ no solo normalmente não atende à demanda das gramíneas. Desta forma, a adubação nitrogenada se constitui em uma importante ferramenta a ser utilizada, pois o nitrogênio influencia positivamente os componentes de rendimento e, consequentemente, o rendimento de sementes (Jornada et al. 2005). Porém, em pastagens tropicais extensivas, adubações de manutenção raramente são realizadas, principalmente a nitrogenada, pois o nitrogênio é o insumo de custo mais elevado para as pastagens (Restle et al.,1999). Sua eficiência, entretanto, depende do nível de fertilidade do solo, das exigências de cada espécie, das condições de temperatura e umidade e da época de aplicação (Humphreys e Riveros, 1986).

O fósforo é um dos elementos que o solo armazena temporariamente e transforma, por isso talvez seja o elemento que mais frequentemente limita a produção vegetal. Todavia, o potássio é, depois do nitrogênio, o elemento mais exigido pela maioria das plantas cultivadas. (Malavolta, 1976).

$\mathrm{Na}$ literatura são encontradas poucas referências sobre o efeito da fertilização das pastagens sobre a produção e a qualidade das sementes, contudo, Conde e Garcia (1988) verificaram que o nitrogênio teve marcante influência sobre o aumento de produção e sobre a qualidade das sementes. Garcia et al. (1989), estudando a influência do nitrogênio, cortes e épocas de colheita na produção de sementes de $B$. decumbens, verificaram que o nitrogênio teve grande influência sobre o aumento de produção de sementes. Num experimento conduzido por 2 anos em Cuba, por Febles et al. (1994), utilizando-se doses de 0,100 e $200 \mathrm{~kg} \mathrm{ha}^{-1} \mathrm{ano}^{-1} \mathrm{de} \mathrm{N}$, observaram que o maior rendimento de semente foi alcançado no segundo ano com valores entre 35 e $40 \mathrm{~kg} \mathrm{ha}^{-1}$ de semente pura, para 100 e $200 \mathrm{~kg} \mathrm{ha}^{-1}$ ano $^{-1}$ de $\mathrm{N}$, respectivamente em campo destinado a produção de sementes.

Em um estudo sobre aplicação de doses de nitrogênio 
em milheto, a eficiência de aplicação de $\mathrm{N}$ no rendimento de sementes mostrou-se positivamente correlacionada com a densidade de panículas. Os maiores rendimentos de sementes foram obtidos com a aplicação de $115 \mathrm{~kg} \mathrm{~N} \mathrm{ha}^{-1}$ (Mesquita et al., 1998).

O objetivo deste estudo foi verificar o efeito de doses de nitrogênio e fósforo e de doses de nitrogênio e potássio sobre a produção e a qualidade de sementes de Brachiaria humidicola (Rendle) Schweick.

\section{MATERIAL E MÉTODOS}

O trabalho foi conduzido em canteiros demarcados em pastagens de Brachiaria humidicola (Rendle) Schweick, implantadas há aproximadamente 15 anos, no Setor de Caprinocultura do Instituto de Zootecnia da Universidade Federal Rural do Rio de Janeiro, no período de 09 de dezembro de 2002 a 15 de janeiro de 2003. A topografia é plana e o clima AW na classificação de Köppen, (Ometto, 1981), apresentando duas estações distintas, uma seca, que se estende de abril a setembro e outra quente e chuvosa, que se estende de outubro a março. Levantamentos dos últimos dez anos, segundo informações da Estação Meteorológica da PESAGRO-RIO, mostram que a precipitação média anual é de $1217 \mathrm{~mm}$, onde as maiores precipitações ocorrem normalmente no período verão-outono, concentrando-se entre dezembro (172 mm), janeiro $(187 \mathrm{~mm})$ e fevereiro (162 $\mathrm{mm})$, com $42 \%$ da chuva total anual. As temperaturas médias anuais máximas e mínimas são, respectivamente, $29,8{ }^{\circ} \mathrm{C}$ e $20,1^{\circ} \mathrm{C}$. O solo da pastagem antes do início dos experimentos apresentava a seguinte composição química, de 0 a $20 \mathrm{~cm}$ de profundidade: $\mathrm{pH}=6,0 ; \mathrm{Al}=0,0 ; \mathrm{Ca}=2,0 \mathrm{cmol} / \mathrm{dm}^{3} ; \mathrm{Mg}$ $=1,5 \mathrm{cmol} / \mathrm{dm}^{3} ; \mathrm{P}=10 \mathrm{mg} / \mathrm{dm}^{3} ; \mathrm{K}=47 \mathrm{mg} / \mathrm{dm}^{3}$, Matéria Orgânica $=1,34 \%$.

Foram conduzidos dois experimentos em delineamento de blocos ao acaso em esquema fatorial, com quatro repetições, sendo utilizadas no primeiro experimento quatro doses de nitrogênio $(0,100,200$ e $400 \mathrm{Kg} / \mathrm{ha})$ e quatro doses de potássio $(0,100,200$ e $400 \mathrm{Kg} / \mathrm{ha})$ e no segundo experimento três doses de nitrogênio $(0,100$ e $200 \mathrm{Kg} / \mathrm{ha})$ e três doses de fósforo $(0,50$ e $75 \mathrm{Kg} / \mathrm{ha})$.

As unidades experimentais foram constituídas por canteiros demarcados de $4 \mathrm{~m}^{2}$, comáreaútil de $2 \mathrm{~m}^{2}$ centrais. Após o corte de nivelamento dos canteiros com roçadeira mecânica (10 cm de altura, da base para o ápice), foram distribuídos a lanço os adubos nitrogenados, potássico e fosfatado a serem estudados, sendo que os mesmos foram aplicados em uma única dose. A colheita das sementes ocorreu 24 dias após início da emergência das inflorescências (de 5 a 10 inflorescências/ $\mathrm{m}^{2}$ ). Foi utilizado método manual de colheita, cortando-se todas as inflorescências, nos $2 \mathrm{~m}^{2}$ centrais de cada canteiro e colocando-as numa superfície forrada, sendo depois cobertas com lona plástica. Ao término de quatro dias, as sementes que se desprenderam das inflorescências foram recolhidas, secas ao ar livre, ensacadas e levadas ao laboratório para análises, sendo posteriormente pesadas e contadas manualmente. Para o teste de germinação utilizaram-se quatro repetições de 100 sementes semeadas em caixas do tipo gerbox, sobre papel, umedecido com água destilada na quantidade correspondente a três vezes o peso do papel substrato. As sementes foram colocadas em germinador nas temperaturas de $15-30{ }^{\circ} \mathrm{C}$ e com 12 horas de luz. As avaliações das plântulas foram realizadas aos 7 e 21 dias, conforme Brasil (1992). Antes do teste de germinação as sementes foram escarificadas com ácido sulfúrico concentrado $\left(\mathrm{H}_{2} \mathrm{SO}_{4}\right)$ por 10 minutos e depois lavadas em água corrente.

Os resultados referentes às produções foram convertidos para $\mathrm{kg}$ de sementes/ha e em número de sementes/ ha, e porcentagem de germinação foram submetidos à análise de variância pelo Sistema de Análises Estatísticas Sisvar (Ferreira, 2002), e a comparação entre médias foi feita pelo teste de Tukey, admitindo-se valores de $5 \%$ de probabilidade, para verificar diferenças entre as doses dos nutrientes aplicados. Para a produção de sementes, $\mathrm{em} \mathrm{kg} / \mathrm{ha}$ e número de sementes (milhões de unidades/ha), foi detectado efeito das doses de nitrogênio, assim, procedeu-se a análise de regressão.

\section{RESULTADOS E DISCUSSÃO}

No primeiro experimento, houve efeito significativo apenas $(\mathrm{P}<0,05)$ para doses de nitrogênio sobre a produção de sementes, tanto em número quanto em peso, e para a porcentagem de germinação de sementes de Brachiaria humidicola (Tabela 1). As doses de potássio não tiveram efeito significativo na produção nem na qualidade das sementes, apesar dos valores obtidos pela análise de solo apresentaremse médios $\left(47 \mathrm{mg} / \mathrm{dm}^{3}\right)$ para pastagens, segundo Almeida et al. (1988). Estes resultados corroboram com os obtidos por Deminicis et al. (2004) e Pereira et al. (2004) que, estudando a produção de sementes de Brachiaria decumbens Stapf sob diferentes estratégias de calagem e adubação nitrogenada, fosfatada e potássica, em Bananal, SP e em Paty do Alferes, $\mathrm{RJ}$, respectivamente, observaram que não houve efeito tanto das estratégias de calagem como das fertilizações sobre a produção das sementes.

Os resultados obtidos no presente estudo para porcentagem de germinação das sementes estão de acordo com Campos e Sader (1987) que avaliando a influência da adubação potássica na qualidade de sementes de Helianthus annuus L., 
observaram que o aumento da aplicação de doses de potássio não afetou a qualidade das mesmas. Todavia, estes resultados não concordam com os observados por Nakagawa et al. (2001) onde estes autores estudando o efeitos da adubação potássica sobre a qualidade de sementes de Avena strigosa Schreber, observaram que adubação proporciona aumento da qualidade das sementes e maior capacidade de emergência das plântulas no campo. Pavinato et al. (2008) estudando a aplicação de doses de nitrogênio em Zea mays L. sob irrigação por aspersão, verificaram que máxima produtividade é obtida com o aumento das doses de nitrogênio, mas não há incremento na produtividade com a aplicação de potássio. Estes resultados evidenciam que, em muitas situações, os produtores estão utilizando fertilizantes nitrogenados e potássicos acima do necessário.

TABELA 1. Produção, em $\mathrm{kg} / \mathrm{ha}$ e em número, e qualidade de sementes de Brachiaria humidicola em função de doses de $\mathrm{N}$ e $\mathrm{K}_{2} \mathrm{O}$.

\begin{tabular}{|c|c|c|c|c|c|}
\hline & \multirow{2}{*}{ Dose de $\mathrm{K}_{2} \mathrm{O}(\mathrm{kg} / \mathrm{ha})$} & \multicolumn{4}{|c|}{ Doses de $\mathrm{N}(\mathrm{Kg} / \mathrm{ha})$} \\
\hline & & 0 & 100 & 200 & 400 \\
\hline \multirow{4}{*}{ Peso (kg/ha) } & 0 & $102,47 \mathrm{Ac}$ & $112,42 \mathrm{Ac}$ & $190,31 \mathrm{Aa}$ & $145,74 \mathrm{Ab}$ \\
\hline & 100 & $100,46 \mathrm{Ac}$ & $110,76 \mathrm{Ac}$ & $192,16 \mathrm{Aa}$ & $145,37 \mathrm{Ab}$ \\
\hline & 200 & $100,96 \mathrm{Ac}$ & $109,64 \mathrm{Ac}$ & $192,88 \mathrm{Aa}$ & $143,97 \mathrm{Ab}$ \\
\hline & 400 & $101,09 \mathrm{Ac}$ & $110,87 \mathrm{Ac}$ & $193,09 \mathrm{Aa}$ & $148,37 \mathrm{Ab}$ \\
\hline \multirow{4}{*}{$\mathrm{N}^{\mathrm{o}}$ sementes (milhões/ha) } & 0 & $20,91 \mathrm{Ac}$ & $28,66 \mathrm{Ab}$ & $30,91 \mathrm{Aa}$ & $17,33 \mathrm{Ad}$ \\
\hline & 100 & $20,50 \mathrm{Ac}$ & $28,24 \mathrm{Ab}$ & $30,83 \mathrm{Aa}$ & $17,27 \mathrm{Ad}$ \\
\hline & 200 & $20,60 \mathrm{Ac}$ & $27,95 \mathrm{Ab}$ & $30,53 \mathrm{Aa}$ & $17,12 \mathrm{Ad}$ \\
\hline & 400 & $20,63 \mathrm{Ac}$ & $28,26 \mathrm{Ab}$ & $31,12 \mathrm{Aa}$ & $17,29 \mathrm{Ad}$ \\
\hline \multirow{4}{*}{ G\% } & 0 & $40,00 \mathrm{Ab}$ & $40,50 \mathrm{Ab}$ & $47,00 \mathrm{Ab}$ & $56,75 \mathrm{Aa}$ \\
\hline & 100 & $40,00 \mathrm{Ac}$ & $45,00 \mathrm{Ab}$ & $48,50 \mathrm{Ab}$ & $53,75 \mathrm{Aa}$ \\
\hline & 200 & $44,00 \mathrm{Ab}$ & $45,00 \mathrm{Ab}$ & $48,00 \mathrm{Ab}$ & $56,75 \mathrm{Aa}$ \\
\hline & 400 & $46,00 \mathrm{Ab}$ & $46,50 \mathrm{Aa}$ & $49,75 \mathrm{Aa}$ & $53,25 \mathrm{Aa}$ \\
\hline
\end{tabular}

*Medias seguidas da mesma letra maiúscula na coluna e minúscula na linha, para a mesma variável estudada, não diferem entre si pelo teste de Tukey a $5 \%$.

Os gráficos dos modelos de regressão com as curvas ajustadas e as equações para produção de sementes em função das doses de $\mathrm{N}$ e $\mathrm{K}$ estão representadas na Figura 1, na qual os valores ajustaram-se ao modelo quadrático podendo-se desta forma verificar que a obtenção da máxima produção de sementes (kg/ha) ocorre na dose de $200 \mathrm{~kg}$ de $\mathrm{N} / \mathrm{ha}$.

No segundo experimento, a análise de variância dos resultados demonstrou apenas efeito $(\mathrm{P}<0,05)$ da adubação nitrogenada na produção de sementes, tanto em peso quanto em número de sementes (Tabela 2), onde os maiores resultados de produção foram obtidos quando se aplicou $200 \mathrm{~kg}$ de N/ha, com valores médios de 191,53 kg de sementes/ha. Pela Figura 2 observase que houve aumento linear na produção de sementes em $\mathrm{Kg} / \mathrm{ha}$ em função das doses de $\mathrm{N}$ e $\mathrm{P}$.

Estes resultados estão de acordo com Mecelis e Oliveira (1984), que constataram que o aumento de doses de nitrogênio aumenta a produção de sementes de B. humidicola. Também Garcia (1989), afirmou que o nitrogênio teve influência significativa sobre o aumento na densidade de inflorescências, o número de ramificações por inflorescências e a produção de sementes puras viáveis em Brachiaria spp. Cani (1980) avaliando a influência do nitrogênio e de cortes sobre a qualidade e a produção de sementes do capim-braquiária ( $B$. decumbens), verificou que o nitrogênio teve marcante influência sobre o aumento de produção e sobre a qualidade das sementes. Os trabalhos de Ramos (1977) com B. decumbens em um Latossolo na Colômbia, mostraram resposta significativa dessa espécie na produção de sementes com a aplicação de $100 \mathrm{~kg}$ de N/ha. Hoyos et al. (1997), avaliando o efeito da adubação sobre o rendimento de sementes puras de B. dictyoneura cv. Llanero, concluíram que o $\mathrm{N}$ é o nutriente que mais limita os rendimentos em sementes puras, sugerindo que níveis mínimos de $70 \mathrm{~kg}$ de N /ha são suficientes para bons rendimentos de sementes. Por outro lado, em milho, o aumento da adubação nitrogenada não alterou a qualidade das sementes (Imolesi et al., 2001) nem elevou a produtividade (Cavallet et al., 2000). 
A

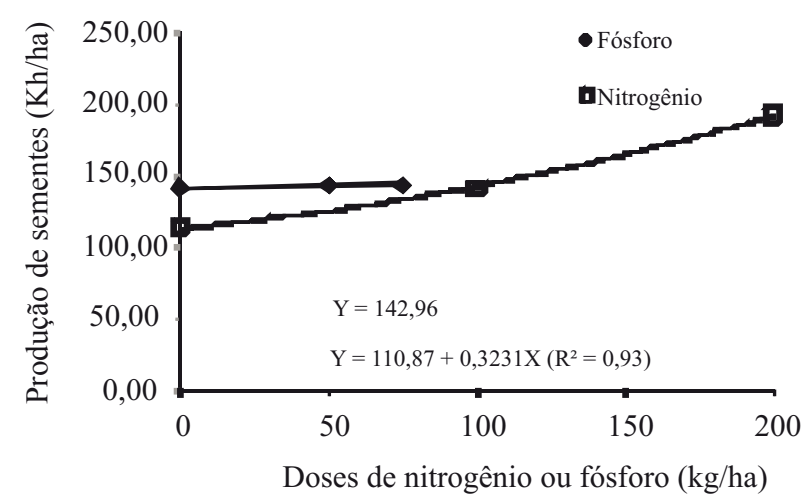

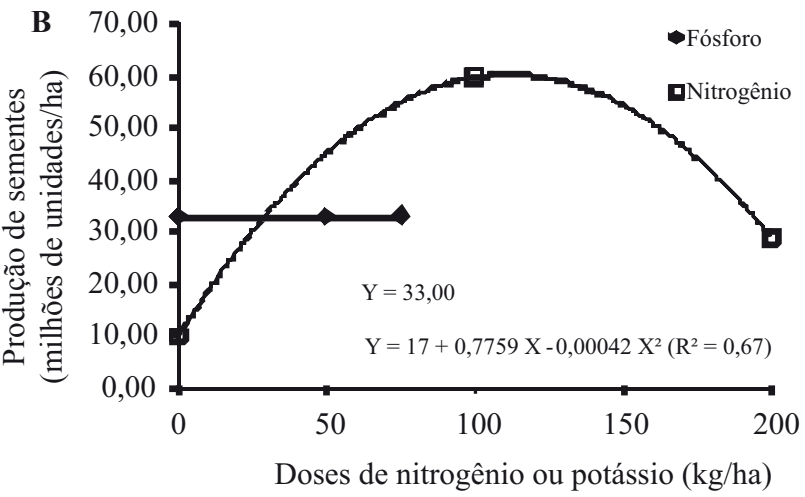

FIGURA 1. Produção de sementes (A) $\mathrm{kg} / \mathrm{ha}$ e (B) número de sementes/ha de capim Brachiaria humidicola em função de doses de $\mathrm{N}$ e $\mathrm{K}_{2} \mathrm{O}$.

TABELA 2. Produção, em kg/ha e em número e qualidade de sementes de Brachiaria humidicola em função de doses de $\mathrm{Ne} \mathrm{P}_{2} \mathrm{O}_{5}$.

\begin{tabular}{|c|c|c|c|c|}
\hline & \multirow{2}{*}{ Dose de $\mathrm{P}_{2} \mathrm{O}_{5}(\mathrm{~kg} / \mathrm{ha})$} & \multicolumn{3}{|c|}{ Doses de N (Kg/ha) } \\
\hline & & 0 & 100 & 200 \\
\hline \multirow{3}{*}{ Peso (kg/ha) } & 0 & $112,79 \mathrm{Ac}$ & $142,53 \mathrm{Ab}$ & $191,07 \mathrm{Aa}$ \\
\hline & 50 & $113,07 \mathrm{Ac}$ & $142,63 \mathrm{Ab}$ & $191,71 \mathrm{Aa}$ \\
\hline & 75 & $112,83 \mathrm{Ac}$ & $141,58 \mathrm{Ab}$ & $191,80 \mathrm{Aa}$ \\
\hline \multirow{3}{*}{$\mathrm{N}^{\mathrm{o}}$ sementes (milhões/ha) } & 0 & $10,15 \mathrm{Ac}$ & $60,15 \mathrm{Aa}$ & $28,70 \mathrm{Ab}$ \\
\hline & 50 & $10,20 \mathrm{Ac}$ & $59,87 \mathrm{Aa}$ & $29,15 \mathrm{Ab}$ \\
\hline & 75 & $10,13 \mathrm{Ac}$ & $59,54 \mathrm{Aa}$ & $29,07 \mathrm{Ab}$ \\
\hline \multirow{3}{*}{ G\% } & 0 & $44,00 \mathrm{Aa}$ & $46,50 \mathrm{Aa}$ & $46,75 \mathrm{Aa}$ \\
\hline & 50 & $45,25 \mathrm{Aa}$ & $46,75 \mathrm{Aa}$ & $45,00 \mathrm{Aa}$ \\
\hline & 75 & $46,25 \mathrm{Aa}$ & $43,75 \mathrm{Aa}$ & $46,25 \mathrm{Aa}$ \\
\hline
\end{tabular}

*Medias seguidas da mesma letra maiúscula na coluna e minúscula na linha, para a mesma variável estudada, não diferem entre si pelo teste de Tukey a $5 \%$.

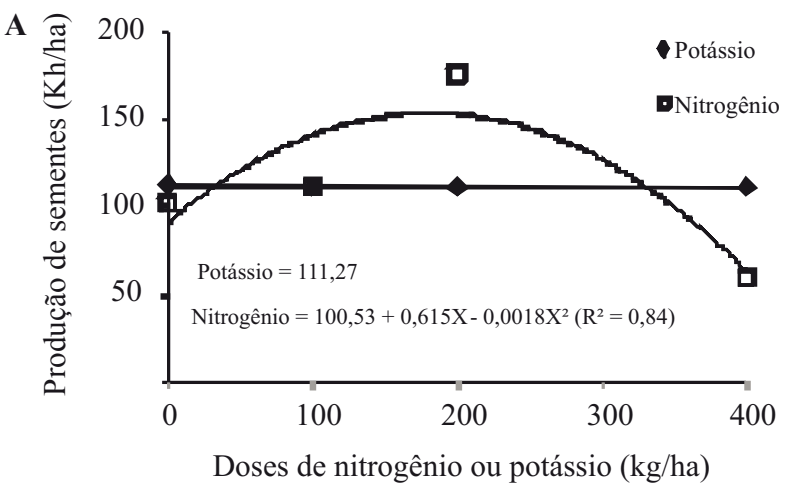

FIGURA 2. Produção de sementes (A) $\mathrm{kg} / \mathrm{ha}$ e humidicola em função de doses de $\mathbf{N}$ e P.

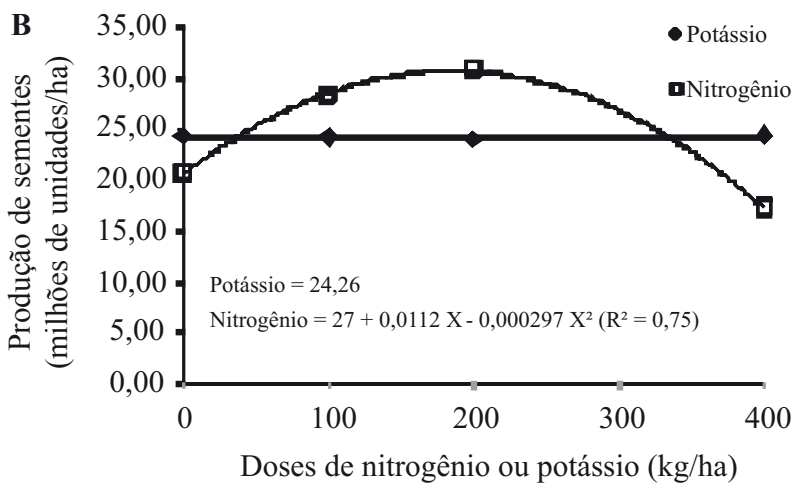

(B) número de sementes/ha de capim Brachiaria 
As doses de fósforo não tiveram efeito significativo na produção nem na qualidade das sementes, apesar dos valores obtidos pela análise de solo apresentarem-se baixos (10 mg/ $\mathrm{dm}^{3}$ ) segundo Almeida et al. (1988). Os resultados apurados no presente estudo não corroboram com Nakagawa et al. (2001) que estudando o efeito da adubação fosfatada sobre os componentes da produção, produtividade e qualidade de sementes de Avena strigosa Schreber, observaram que adubação fosfatada aumenta o número de sementes das panículas do colmo principal e dos perfilhos, resultando em maior produtividade de sementes $(\mathrm{kg} / \mathrm{ha})$ e maior peso das sementes, mas sem afetar a germinação. Esta última consideração está de acordo com o que foi verificado no presente estudo.

\section{CONCLUSÕES}

A adubação nitrogenada afetou positivamente a qualidade e a produção de sementes, tanto em peso quanto em número de sementes de Brachiaria humidicola (Rendle) Schweick.

A adubação com fósforo e potássio não tiveram efeito sobre a produção e a qualidade das sementes.

\section{AGRADECIMENTOS}

UFRRJ-Universidade Federal Rural do Rio de Janeiro.

UENF-Universidade Estadual do Norte Fluminense Darcy Ribeiro.

\section{REFERÊNCIAS}

ALMEIDA, D.L., SANTOS, G.A., DE POLLI, H. et al. Manual de adubação para o Estado do Rio de Janeiro. n² Editora Universidade Rural. Itaguaí, RJ. 1988. 178p.

ANDRADE, R.P. Pasture seed production tecnology in Brazil. In: INTERNATIONAL GRASSLAND CONCRESS, 19, 2001, São Pedro. Proceedings... Piracicaba: FEALQ, 2001. p.129-132.

ANDRADE, R.P.; VILLAS BOAS, H.; SILVEIRA, G.C.; PAIVA, L.A parceria Embrapa-Unipasto e seu impacto na pesquisa e desenvolvimento de pastagens tropicais do Brasil. Brasília: Abrasem, 2004. Disponível em: < www. abrasem.com.br >. Acesso em: 5 maio. 2005.

BRASIL. Ministério da Agricultura e Reforma Agrária. Secretaria Nacional de Defesa Agropecuária. Departamento Nacional de Defesa Vegetal. Coordenação de Laboratório Vegetal. Regras para análise de sementes. Brasília, DF,
1992. 365p.

BOTREL, M.A.; ALVIM, M.J.; XAVIER, D.F. Avaliação de gramíneas forrageiras na região sul de Minas Gerais. Pesquisa Agropecuária Brasileira, v.34, n.4, p.683-689, 1999.

CAMPOS, M.S.O.; SADER, R. Efeito do potássio na produção e qualidade das sementes de girassol. Revista Brasileira de Sementes, v.9, n.3, p. 19-27, 1987.

CANI, P.C. Influência do nitrogênio, cortes e épocas de colheita sobre a produção e qualidade das sementes do capim braquiária (Brachiaria decumbens Stapf). 1980. 62f. Dissertação Mestrado (Mestrado em Zootecnia) Universidade Federal de Viçosa, Viçosa, 1980.

CAVALLET, L.E.; PESSOA, A.C.S.; HELMICH, J.J.; HELMICH, P.R.; OST, C.F. Produtividade do milho em resposta à aplicação de nitrogênio e inoculação das sementes com Azospirillum spp. Revista Brasileira de Engenharia Agrícola e Ambiental, v.4, n.1, p.129-132, 2000.

CONDE, A.R.; GARCIA, J. Efeito de níveis e épocas de aplicação de nitrogênio na produção e qualidade das sementes do capim-colonião. Revista Brasileira de Sementes, v.10, n.1, p.33-42, 1988.

DEMINICIS, B.B.; PEREIRA, P.P. ABREU, J.B.R.; OLIVEIRA, V.C. SATYRO, R.H.; SIMONE, G.A.; SANT'ANA, N.F.; BEZERRA, L.L.; ALMEIDA, J.C.C. Produção de sementes de capim-braquiária (Brachiaria decumbens Stapf) em pastagens degradadas submetidas a diferentes estratégias de calagem e adubação em Bananal - SP. In: CONGRESSO INTERNACIONAL DE ZOOTECNIA, 6, 2004, Brasília. Anais... Brasília, DF: ABZ, AZOO-DF, 2004. CD-ROM.

DIAS, M.C.L.L.; ALVES, S.J. Teste de tetrazólio em sementes de Panicum maximum e Brachiaria brizantha. IAPAR, Londrina, 2001. 11p. (Apostila).

FAGUNDES, J.L.; FONSECA, D.M.; GOMIDE, J.A. Acúmulo de forragem em pastos de Brachiaria decumbens adubados com nitrogênio. Pesquisa Agropecuária Brasileira, v.40, n.4, p.397-403, 2005.

FERNANDES, C.D.; MARCHI, C.E.; JERBA, V.F.; BORGES, M. de F. Patógenos associados às sementes de forrageiras tropicais e estratégias de controle. In: ZAMBOLIM, L. (Ed.). Sementes, qualidade fitossanitária. Viçosa: UFV, 2005. p.183-213.

FERREIRA, D.F. SISVAR Sistemas de análises de variância para dados balanceados: programa de análises estatísticas e planejamento de experimentos. Versão 4.3. Lavras: UFLA, 2002. (CD-ROM).

FEBLES, G.; RUIZ, G.; PADILLA,C.; GUISADO, I.; 
AGUIAR, M.; DIAZ, L.E. The effect of the nitrogen dosage and management on seed and forage production of Brachiaria decumbens cv. Basilisk. Cuban Journal of Agricultural Science, v.28, n.1, p. 95-99, 1994.

GARCIA，R.; CANI，P.C.; OBEID， J.A.; SILVA，R.F. Influência do nitrogênio, cortes e épocas de colheita sobre a produção de sementes de capim-braquiária. Revista da Sociedade Brasileira de Zootecnia, v.18, n.6, p.482-490, 1989.

HOYOS, P.; MOLINA, D.L.; VERA, R.R. Efecto de la fertilización en el rendimiento de semilla de Brachiaria dictyoneura cv. Llanero en la altillanura Colombiana. Pasturas Tropicales, v.19, n.2, p.35-39, 1997.

HUMPHREYS, L.R., RIVEROS, F. Tropical pasture seed production. 3.ed. Rome: FAO. 1986. 203p.

IMOLESI, A.S.; VON PINHO, E.V.R.; VON PINHO, R.G.; VIEIRA, M.G.C.; CORRÊA, R.S.B. Efeito da adubação nitrogenada em características morfo-agronômicas e nos padrões eletroforéticos de proteínas e isoenzimas de sementes de milho. Revista Brasileira de Sementes, v.23, n.1, p.1725, 2001.

JORNADA DA JORNADA, J.B.; MEDEIROS, R.B.; PEDROSO, C.E.S.; SILVA, M.A.; SAIBRO, J.C. Efeito da irrigação, épocas de corte da forragem e doses de nitrogênio sobre o rendimento de sementes de milheto. Revista Brasileira de Sementes, v.27, n.2, p.50-58, 2005.

MALAVOLTA, Manual de química agrícola - nutrição de plantas e fertilidade do solo, Piracicaba, Agronômica Ceres, 1976. 528p.

MECELIS, N.; OLIVEIRA, P.R.P. Componentes da produção de sementes de Brachiaria humidicola: Efeito da adubação nitrogenada e épocas de colheita, Zootecnia, v.22, p.57-71, 1984.

MESQUITA, E.E.; PINTO, J.C.; MORAIS, A.R. Doses de nitrogênio e métodos de semeadura no rendimento de sementes de milheto (Pennisetum americanum (L.) Leeke). Revista da Sociedade Brasileira de Zootecnia, v.27, n.2, p.255-261, 1998.

NAKAGAWA, J.; CAVARIANI, C.; BICUDO, S.J.
Produção e qualidade de sementes de aveia-preta em função da adubação fosfatada e potássica. Revista Brasileira de Sementes, v.23, n.1, p.260-266, 2001.

OMETTO, J.C. Bioclimatologia vegetal. São Paulo: Agronômica Ceres Ltda., 1981. 440p.

PAVINATO, P.S.; CERETTA, C.A.; GIROTTO, E.; MOREIRA, I.C.L. Nitrogênio e potássio em milho irrigado: análise técnica e econômica da fertilização. Ciência Rural, v.38, n.2, p.358-364, 2008.

PEREIRA, F. de A.R.; ORNELAS, A.J.; HIDALGO, E. Avaliação do herbicida metsulfuronmethyl no controle de plantas daninhas em área de produção de sementes de pastagens. Revista Brasileira de Herbicidas, v.1, n.2, p.179-183, 2000.

PEREIRA， P.P.; DEMINICIS， B.B.; ABREU， J.B.R.; BEZERRA, L.L.; SATYRO, R.H.; SIMONE, G.A.; ARAÚJO, S.A.C.; OLIVEIRA, V.C.; ALMEIDA, J.C.C. Avaliação do efeito da fertilização e correção do solo sobre a produção de sementes de capim-braquiária (Brachiaria decumbens, Stapf) em pastagens degradadas no município de Paty do Alferes - RJ. In: CONGRESSO INTERNACIONAL DE ZOOTECNIA, 6, 2004, Brasília. Anais... Brasília, DF: ABZ, AZOO-DF, 2004. CD-ROM.

RAMOS, N. Efecto de la fertilización sobre la producción de semilla de pasto Brachiaria em los llanos orientales. In: INSTITUTO COLOMBIANO AGROPECUÁRIO. Programa Nacional de Fisiologia Vegetal. Informe de Progreso. s.1., 1977. p. 96-107.

RESTLE, J.; ROSO, C.; SOARES, A.B. Produção animal e retorno econômico em misturas de gramíneas anuais de estação fria. Revista Brasileira de Zootecnia, v.28, n.2, p.235-243, 1999.

SKERMAN, PJ.; RIVEROS, F. Tropical grasses. Food and Agricultural Organization of the United Nations: Rome. p.565-568, 1990.

SOUZA, F.H.D. Produção e comercialização de sementes de plantas forrageiras tropicais no Brasil. In: SIMPÓSIO DE FORRAGICULTURA E PASTAGENS, 2, 2001, Lavras MG. Anais... Lavras: Núcleo de Estudos em Forragicultura, UFLA, 2001. v. único. 282p. 